\section{Andrzej K. Tarkowski 1933-2016}

With Andrzej Tarkowski's death we lose the father of modern mammalian embryology, whose desire to understand early development brought out a genius for using simple tools and elegant experiments to give true insights into the earliest events of our lives.

Tarkowski was introduced to embryology as a student at Warsaw University in the 1950 s by August Dehnel, who studied fetal resorption in the common shrew in a field station in Bialowieza Forest, an isolated national park renowned for its primeval forest. This experience convinced Tarkowski that he would be better served by working with laboratory mice, although the study of wild rodents would remain an attraction. During Tarkowski's work on delayed implantation in lactating mice for his $\mathrm{PhD}$ thesis, he noticed a damaged 2-cell-stage embryo that continued to develop. This observation led to experiments in which he destroyed one cell at the 2-cell-stage and showed that the remaining cell could make a mouse, demonstrating totipotency of one of the first two cells. This finding was recognized by Rogers Brambell of North Wales University in Bangor, an expert in implantation. Encouraged by Brambell, Tarkowski published his crucial finding in Nature in 1959 and left Poland, but only for 15 months, to do research in Bangor. There, he again broke new ground by generating the first chimeric mouse embryos. His paper on chimeras appeared in Nature in 1961, soon followed by a similar study from Beatriz Mintz. Independently, they had demonstrated the incredible flexibility of the embryo and in doing so had developed a powerful tool in mammalian embryology.

Tarkowski's work was rooted in Poland and it was to Poland he returned to establish his own laboratory. There, he first proposed his famous 'inside-outside hypothesis' that cell position affects cell fate. Cells inside the embryo give rise to the pluripotent epiblast, from which the embryo proper develops, and outer cells become the trophectoderm and hence the placenta. Although later modified to encompass the effect of early cellular heterogeneity and polarization on biasing cell position and fate, this hypothesis has remained a central tenet of mammalian development.

Tarkowski conducted his research when Poland was under communist control and materials were in short supply. $\mathrm{He}$ circumvented this with the great ingenuity he brought to routine work. For example, we all had to exhale air into sealed boxes containing our mouse embryos to substitute for $\mathrm{CO}_{2}$-filled incubators. He also brought his favourite books, not for their literary value, but because they were the perfect height to prop up his elbows for cutting eggs. This spilled over into equally imaginative approaches to experimental design, inspiring his students to believe that even the most difficult experiments were possible. What he achieved with so few reagents is, in retrospect, astounding. He established a lifeline of support through Chris Graham and Anne McLaren in England, who knew him as Krzysztof. This was an important conduit for reagents difficult to procure in Poland, and an opportunity to experiment with new ideas. In his time spent in Chris's lab in Oxford he tested prototype studies that were later methodically adapted in his own laboratory.

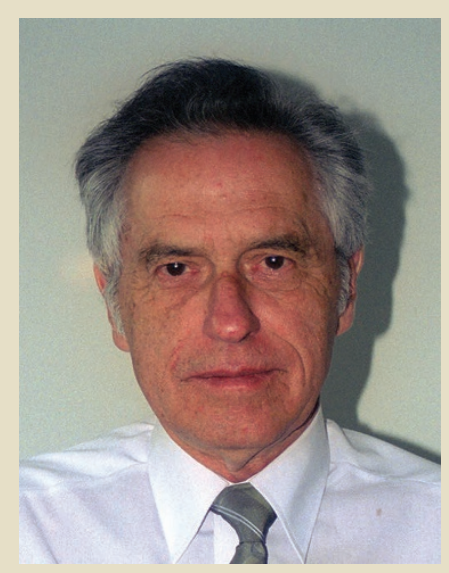

(C) Katarzyna Szczepańska

Forest where Tarkowski was first introduced to embryology, and brought to Warsaw where we were to discover how fond they were of human fingers ... mine! Only after months of using myself as living bait for these wild animals did I ask to switch to rat-mouse chimeras. It was Tarkowski's regret not to get to the bottom of the puzzle of why a foreign sperm or a blastomere's nucleus cannot survive in the cytoplasm of another species. His last project had one aim - to generate chimeras between mice and rats.

Tarkowski was recognized by many awards, including the Albert Brachet Prize of the Royal Academy of Belgium (1980), the Polish National Award (1980), the Japan Prize (2002) and the Foundation for Polish Science Prize (2013). His dedication to science meant that he avoided administration, with the exception of helping people about to be expelled for political reasons during martial law. His legacy is carried forward by his former students and colleagues working in Poland, including Jacek Modlinski, Ania Ciemerych-Litwinienko, Ewa Borsuk, Marek Maleszewski, who maintain the Polish school of embryology, and rebels like myself and Jacek Kubiak, who escaped to have 'easier' scientific lives outside Poland. Discussions with Krzysztof are fondly remembered by the club of wonderful embryologists from when embryology was at its height in Oxford, which includes Chris Graham, Richard Gardner, Ginny Papaioannou and Janet Rossant.

Biology fascinated Tarkowski and was also an important part of his life outside the lab, in which photography was his passion. His models were from the natural world - the abstract designs drawn from plant life. His wonderful wife Teresa and daughter Monika were stars to him and formed a keystone in his life. Tarkowski was a unique human being, who uncovered some of life's most profound secrets and shared them with everyone. His influence on the field, and on his colleagues, friends and family, has been exceptional and he will be sorely missed.

\section{Magdalena Zernicka-Goetz}

Magdalena Zernicka-Goetz is at the University of Cambridge, Downing Street, Cambridge, CB2 3EG, UK.

e-mail: mz205@cam.ac.uk 